\title{
Supporting Students' Understanding of Area Measurement Through Verknippen Applet
}

\author{
Wahid Yunianto \\ SEAMEO QITEP in Mathematics, Yogyakarta, INDONESIA \\ $<$ wahid_yunianto@yahoo.co.id>
}

\begin{abstract}
In this paper, we will present a case study of the possibility of using an applet in the teaching and learning of area measurement. The researcher investigated how an applet can support students' understanding of the concept of conservation of area. Data were collected through video registration, students' work and interviews. Students were involved in six meetings around the learning of area measurement. In some meetings, students worked on hands-on activities. For instance, through cut and paste activities, students would acquire the concept of conservation of area. They witnessed that if there is no part thrown away when cutting and pasting a figure, the area will not change. However, when it comes to reshaping a figure into another one (rectangle), students would use trial and error. Some students would face difficulties reshaping the figures into a rectangle. They could not undo their cutting when they failed in making a rectangle. To some extent, hands-on activities will constrain students. The use of an applet which provides the same activities will help students to be more creative in reshaping a figure. The school has no internet facilities to access the applet. To see the possibilities of an applet to support students understanding, after some weeks, we invited students to play with the applet. We recorded students' activities in working with the applet. Students were enthusiastic to try when they could not solve the problems. After the session with the applet, students worked on similar problems on paper. They successfully dealt with the problems. It reveals that students prefer to use the applet because they can easily try again when they fail. It shows that students could understand how to measure areas of irregular figures.
\end{abstract}

Keywords: Measurement, Area, Applet, Teaching Area

\section{Introduction}

This paper is a continuation of a larger study of area measurement. Area is an amount of two-dimensional surface that is contained within a boundary and that can be quantified in some manner (Baruto \& Nason, 1996). Reynolds \& Wheatley (1996) stated that area measurement assumes that: a suitable two-dimensional region is chosen as a unit; congruent regions have equal areas; regions do not overlap; and, the area of the union of two regions is the sum of their areas. The design learning sequences in the previous study apply all the concepts (Yunianto, 2014). However, the researcher started the lesson by focusing on the comparing areas to ignite an overlapping strategy. Afterward, students will cut and paste if they are provided with cutting tools.

The researcher focuses on supporting students understanding of area measurement through reallotment activities. Students participated in designed activities in six meetings. 
The activities were designed and developed within realistic mathematics education (RME) tenets. Reallotment means an activity of redistributing or reallocating or rearranging something (Holt, Rinehart, \& Winston, 2003). In area measurement, it embeds the concepts of conservation of area in which the area of a figure is preserved when it is reshaped. Some studies have shown that understanding the conservation of area is important and fundamental before students learn area measurement (Kordaki, 2003). To master this concept, students can experience activities of cutting, pasting and rearranging a figure into a new one with an equal area (Kordaki, 2003). Therefore, reallotment activities were placed in the designed lessons involved cutting, pasting and reshaping into a rectangle. We planned to integrate ICT in the teaching and learning in the designed lessons. Considering that the school's facilities are not supported with the internet access, the researcher omitted the use of an applet in the initial designed activities. Therefore, in the six meetings, the applet was not used and only involved the hands-on activities.

We found that students could attain their understanding of the concepts of area measurement through hands on activities (Yunianto, 2014). Students could understand the meaning of area; the region inside within a boundary. They witnessed that if no parts are wasted in the cutting and pasting, then the area would not change. Reshaping into a rectangle would help students to measure areas of others quadrilaterals or even triangles. Dealing with cutting and pasting to reshape a figure into a rectangle, some students had difficulties once they failed in making a rectangle from the figures. Students could not easily undo what they had made because they had also glued it.

Some research studies show that ICT or any applets can support students' understanding and improve their motivation. There are three crucial factors for the success of digital technology in mathematics education including the design of the digital tool, the role of the teacher and the educational context (Drijvers, 2013). The researcher chose the Verknippen applet because its design for the tasks is so powerful to support students' understanding of the concept of conservation of area. Conservation of Area and its Measurement (C.AR.ME) microworld had been designed and used to support students' understanding of conservation of area (Kordaki, 2003). In this paper, we raise a research question: to what extent the Verknippen applet could help students learn concept of conservation area. 


\section{Methodology}

The purpose of this study is to investigate whether the Verknippen applet can be used to support students' understanding the conservation of area. The applet can be accessed from the following address: http://www.fi.uu.nl/toepassingen/00457/serie1.html. It has been two weeks since the last meeting ended. The researcher selected four students from a classroom used previously in the six meetings teaching and learning of area measurement to participate in this study. These students are considered as medium and high performance students based on the classroom teacher and observations. Data collected through video registration, screen recording and students’ work.

\section{Result and Discussion}

Since the researcher only used one laptop to conduct this study, in turn, students worked on the applet. While students were working on the applet, the program Camtasia recorded the screen. All student steps can be captured and saved into a video data file. This recording can be used as an assessment item because it captures how students solved the tasks. Through this recording, the researcher might see students' different strategies or even the same strategies. After a student finished with the tasks on the applet, then s/he worked on paper based tasks. The applet has five series of task with each consisting of nine to ten tasks. If they successfully made a rectangle the button became green. The researcher sometimes interviewed students informally while they were working on the tasks.

\section{Students various strategies}

It was obvious that working with the Verknippen applet allowed students to try out and experience the tasks many times. They could cut and paste many times in order to reshape a figure into a rectangle. When they made mistakes and got difficulties, they could start over on the task. The following is the display of the applet with Dutch language. It was not a big problem for students with the language. The researcher let students work with the applet first and asked them to make a rectangle from figures. The applet asks students whether they can make a rectangle (figure 1). After students understood what they should do, in turn, they did the task. 


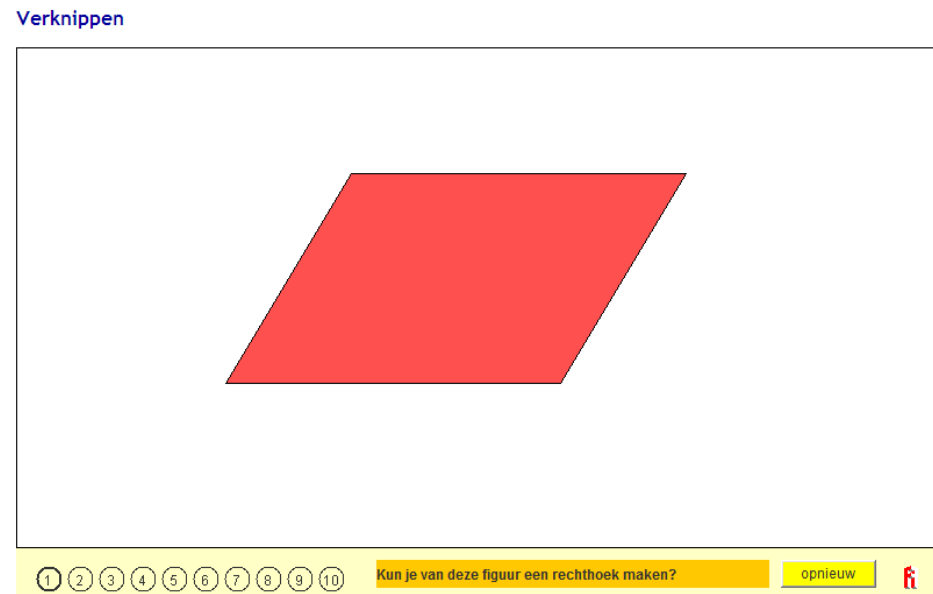

Figure 1: The task in the Verknippen applet serie1

The following figures are captured from the screen recording.
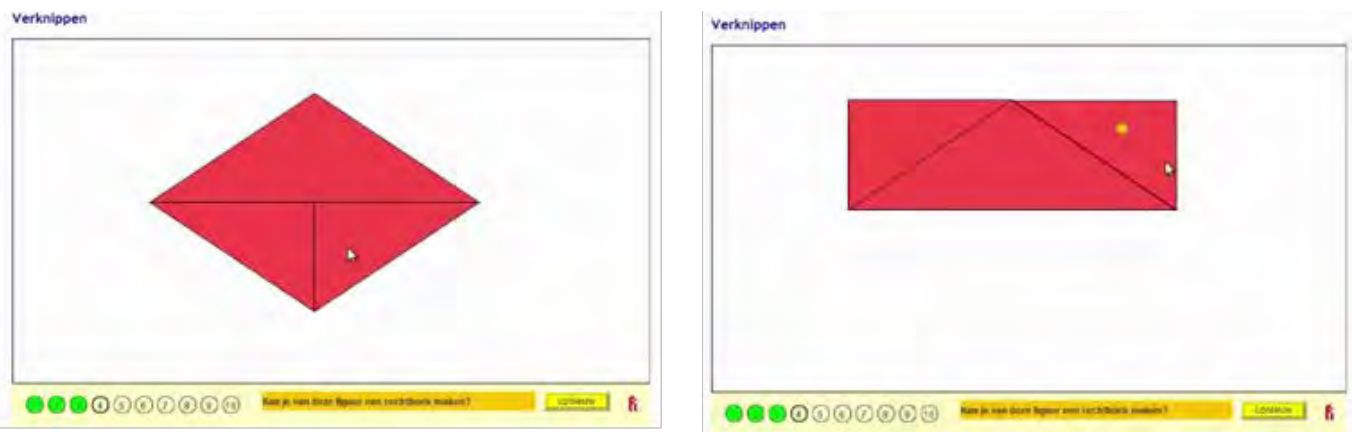

Figure 2: Student's work on the rhombus in figure 1

It can be seen that this student divided the rhombus into two parts (upper and lower). S/he then divided the lower part into two parts. Finally, s/he moved the last two parts into the upper part and made a rectangle. Another student did differently as seen in figure 3 . In fact, it is not so much different but students might do what they think is easier to do.
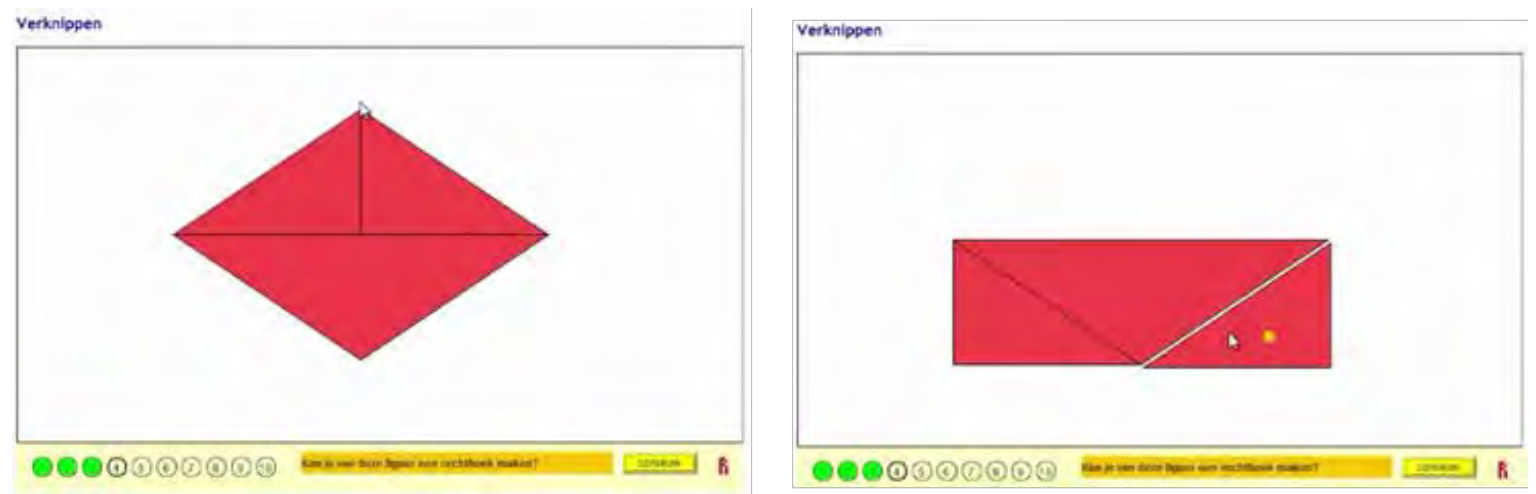

Figure 3: Another student's work on the rhombus in figure 1 
In doing task 7, students also had different ways of reshaping the irregular figure (figure 4). This task is more difficult compared to previous ones.

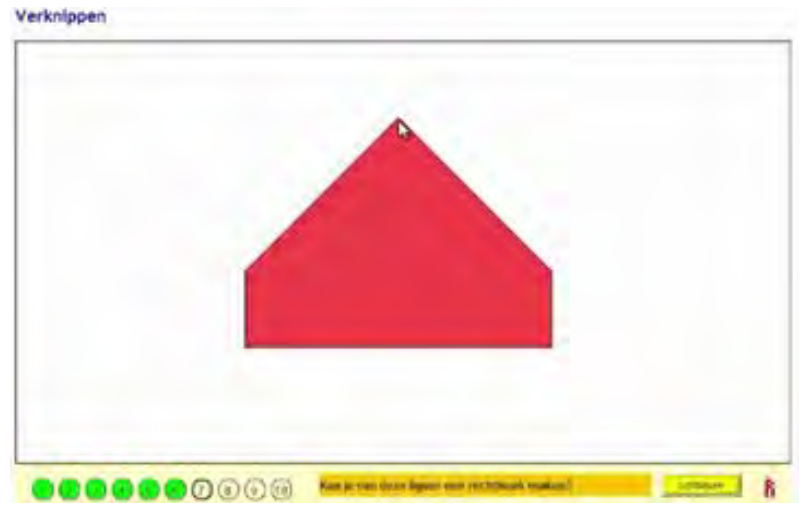

Figure 4: Task 7 in the Verknippen applet

Students had to think how to reshape this figure into a rectangle. In previous tasks, students could easily see parts will be cut and moved. In this task, students tried out by firstly dividing the figure equally into two parts. They arranged the parts to see the possibilities of creating a rectangle. Some students made a vertical rectangle, and others made it horizontally.
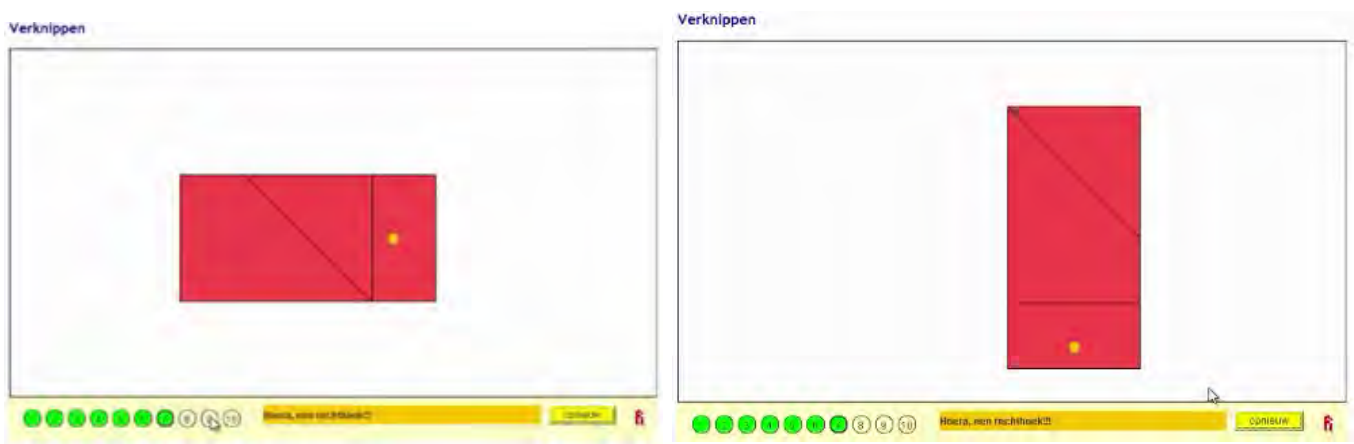

Figure 5: Students’ rectangles on Task 7

One student who is considered as a high performance student asked for more challenging tasks. Then the researcher provided other tasks in the applet. Task 1 to task 4 , s/he confidently made it. When it came to task 5 , s/he faced troubles. S/he could not make it easily into a rectangle. S/he tried many times but failed. Friends who were sitting next to he/r tried to help. 


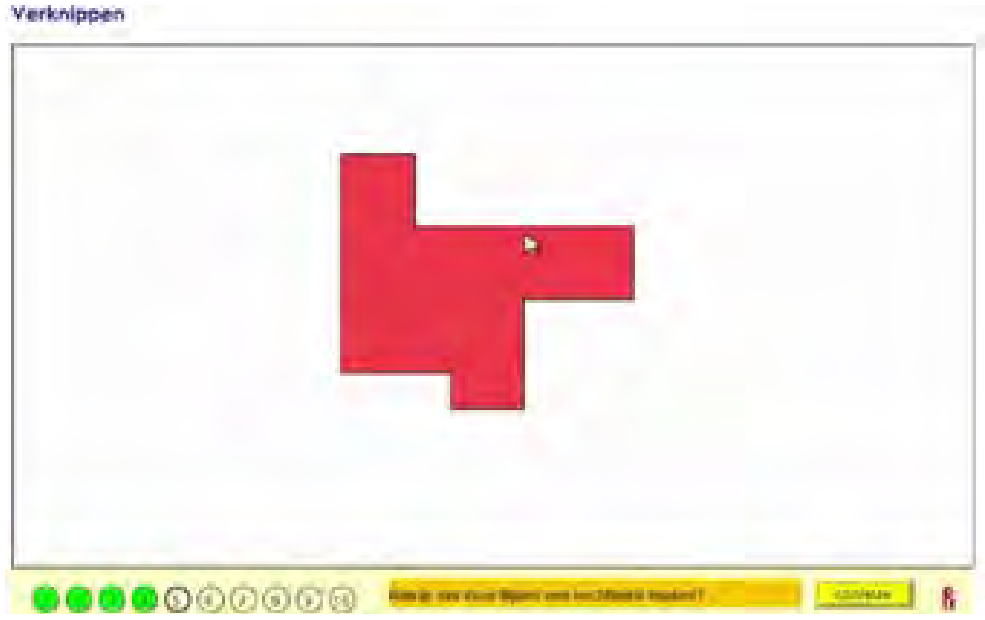

Figure 6: Task 5 in the Verknippen applet serie 2

The following figures show how she failed to make a rectangle

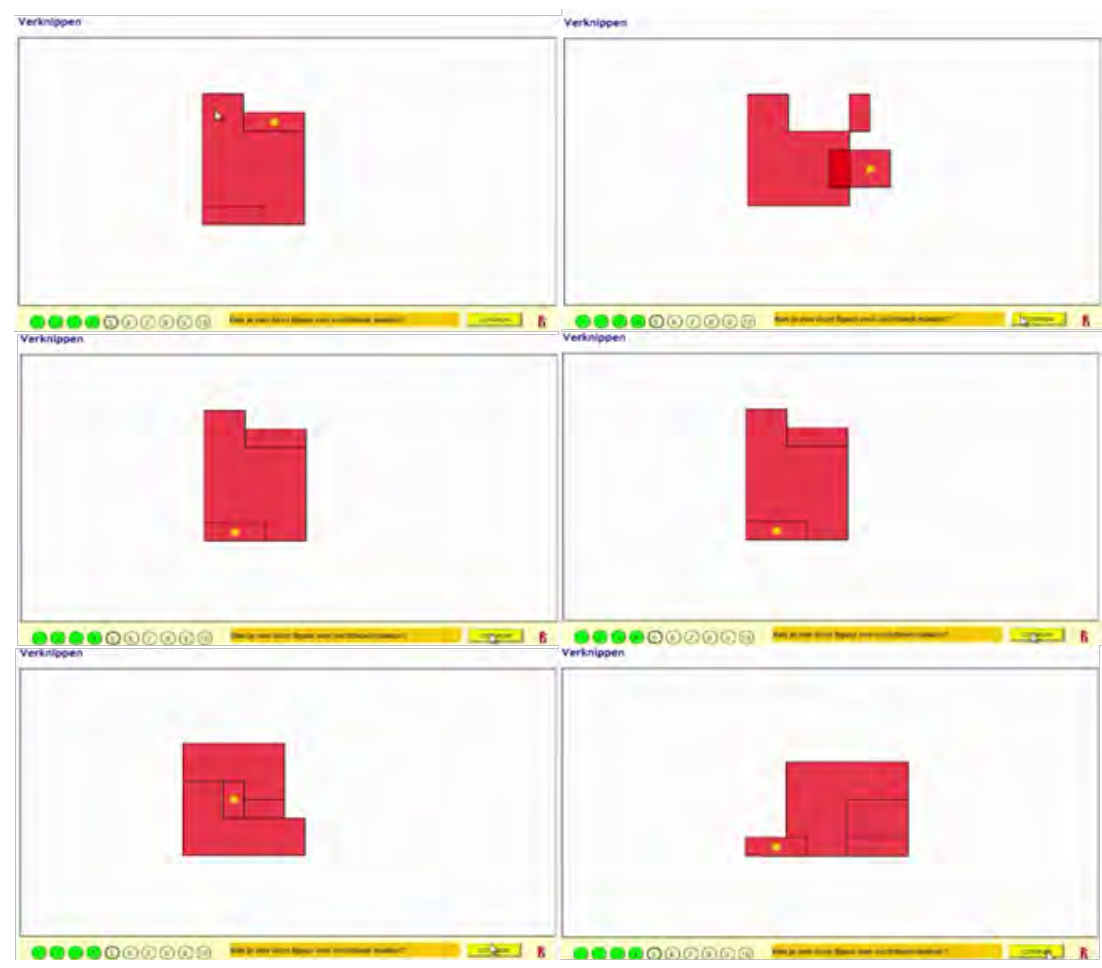

Figure 7: Student could not make a rectangle

More than six times s/he failed to reshape the figure into a rectangle. One friend asked to try it out. S/he gave the friend a try. Interestingly, the friend could not make it on the first trial. However, the friend finally made it and felt happy. 


\section{Student motivation}

In an informal interview, the researcher asked students about their opinion related to the activities in the applet. The following is a brief segment that illustrates a common response.

$\mathrm{R} \quad$ : Which one is better, the cut and paste activity or playing this applet?

SD : This one (the applet) If we made mistakes, we can start it over again

$\mathrm{R} \quad$ : So, which one is better?

SA \&SD : : This applet indeed

SA $\quad$ : I could start it over

From this segment, students argued that the applet is better because they could start over and do the tasks provided in the applet. Compared to cutting and pasting paper where students could not redo what they have cut. When they have reshaped the figured improperly, then they would give up since they could not do it again. The flexibility of the applet proved that the feature helps students encourage them to have more strategies.

Another segment caught in the recording was the conversation among students while one student working with the applet. The researcher and the persuaded a student to give up but she did not want to give up.

$\mathrm{R}$

SC

SA,B,D : (Singing a song)

SC : : Stop singing

SA : (Still singing)

SC $\quad$ : I cannot divide into two (still working on the task)

SA,B,D : (keep singing)

SC

SB

$\mathrm{SC}$

$\mathrm{SD}$

SC

SB

SC
: I cut too many parts so that I cannot cut it again, don't I?

: (keep singing)

: Ah...(cannot concentrate),(starting over the task), hahaha (laughing)

: Cut this part, ok?

: Ok

: Cut also this part

: This part? 
SD

$\mathrm{SC}$

SB

SA

SC

$\mathrm{SD}$

$\mathrm{SC}$ : Yes

: Then, what should I do?

: Rotate that part! Cut the below part into two, or even three!

: If you divide it into three then there is no part to be cut later

: (Keep trying)

: Just give up!

: No way, if I give up I will be curious later

It is obvious from both sentences that this student was not easily to give up. S/he kept trying to solve the task. The task is more difficult than the tasks in serie 1 . Therefore, it is indeed not easy to reshape the figure into a rectangle. The task also made this student curious if s/he did not finish it. Thus, we can say that this applet could motivate students because the tasks challenge students. For the smarter students, they can try out other series of the applet. Therefore, the smarter students still have opportunities to try more difficult tasks in order to maintain their motivation.

\section{Students' understanding of the concept}

After students finished the tasks in the applet they worked on a worksheet. The following figures show how they answered the questions.

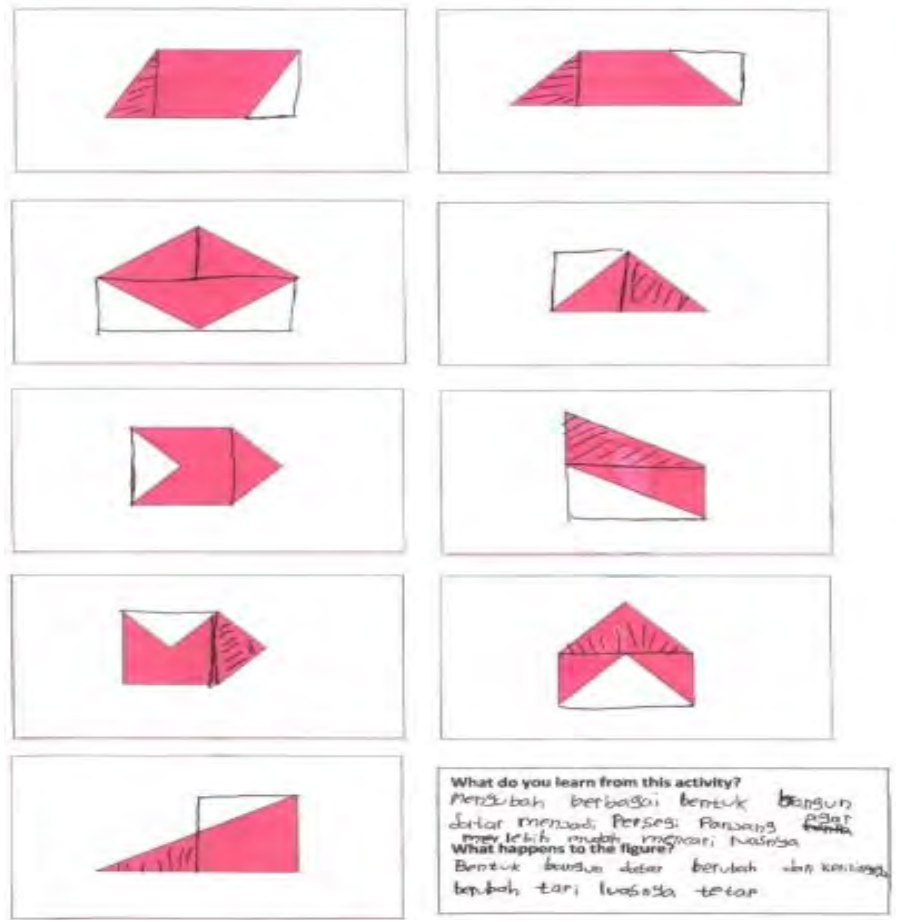

Figure 8: Student's answer on the worksheet 

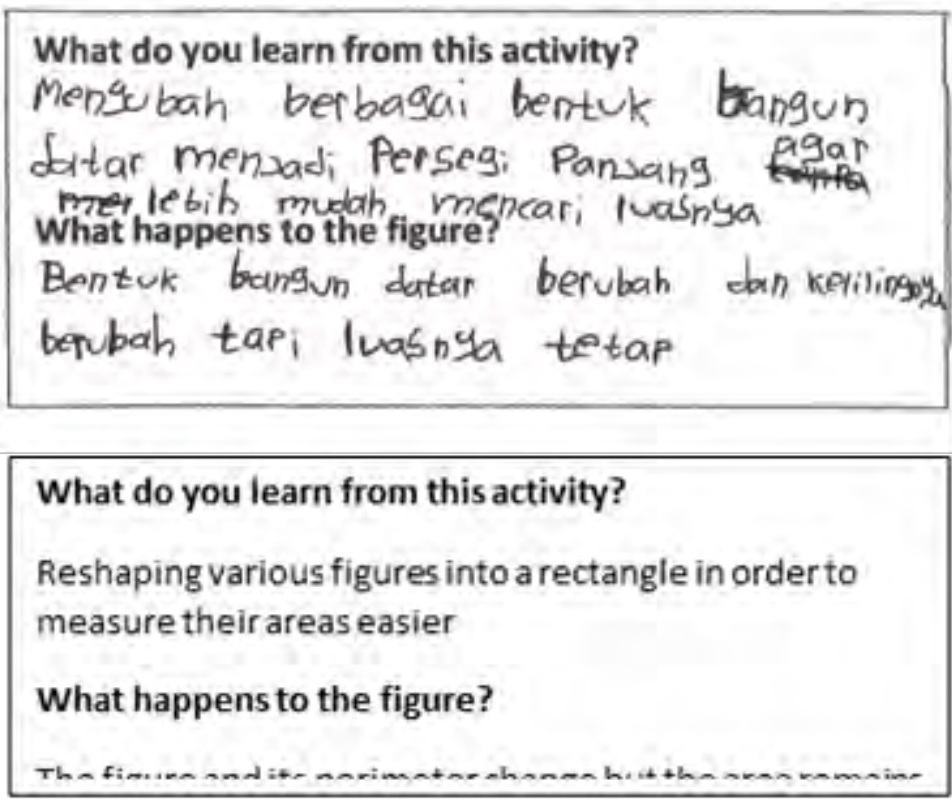

Figure 9: Student's explanation about the activity

Figure 8 and figure 9 is one student's work. Even though the tasks on the paper pencil worksheet were simple, students could manage to make a rectangle from its initial figure by drawing it without cutting. Most students answered that the activity is about reshaping into a rectangle to measure easier the area. They also stated that the shape and its perimeter change and area remain still. Therefore, it could be said that students got the point of what they did in the activity. They could understand that reshaping a figure into a rectangle will help them to measure its area. They also could understand the concept of conservation of area.

This study has its limitation in which only a few students participating this study and cannot be generalized to a real classroom setting. Therefore the role of the teacher did not appear in this setting. However, it is important to notice that students were motivated in learning and they could grasp the mathematical concept from the activity they did in the applet.

\section{Conclusion}

The answer to the research question: Do the tasks in the Verknippen applet let students have more strategies in reshaping into a rectangle? Evidence showed that students could start over the tasks and try them again when they faced difficulties. This is one of the strengths of the use of this applet. Students were motivated to do the tasks more than once. Different series of the tasks also provided students with more challenging tasks. To see the progress from the tasks in the applet to the paper pencil task, it could be seen that students could 
reshape the figure into a rectangle by just making drawing and arrows on it. To some extent, students move from real cutting and pasting in the applet into drawing the sketch. In drawing, students needed to determine the shape of a rectangle they were going to make. Therefore, they were forced to think more rather than just try to cut and paste. Students also could understand that reshaping into a rectangle will not change the area of its initial figure. In addition, the applet could be used if learning designs support students' development of the concept.

\section{Acknowledgements}

The author would like to thank his colleagues for their valuable comments and input.

\section{References}

Baturo, A., \& Nason, R. (1996).Student teachers' subject matter knowledge within the domain of area measurement. Educational Studies in Mathematics, 31(3), 235-268.

Drijvers, P. (2013). Digital technology in mathematics education: why it works (or doesn't). Pna, 8(1), 1-20.

Holt, Rinehart, \& Winston (2003).Reallotment Britannica Mathematics in Context Teacher Guide. Illinois: Encyclopædia Britannica, Inc.

Kordaki, M. (2003).The effect of tools of a computer microworld on students' strategies regarding the concept of conservation of area. Educational Studies in Mathematics, 52(2), 177-209.

Reynolds, A., \& Wheatley, G. H. (1996). Elementary students' construction and coordination of units in an area setting. Journal for Research in Mathematics Education, 564-581.

Yunianto, W. (2014).Supporting $7^{\text {th }}$ grade students' understanding of the area measurement of quadrilaterals and triangles through reallotment activities. Master thesis. Sriwijaya University 